\title{
Correspondence
}

\author{
Draft Code of Practice \\ DEAR SIRS \\ I wonder if I might add my pennyworth to the no doubt \\ voluminous correspondence on this matter (Comments of \\ the Royal College of Psychiatrists on the Mental Health Act \\ 1983 Draft Code of Practice, Bulletin, August 1986, 10, \\ 194-195).
}

In general I very much agree with the sentiments expressed-in particular that "the Code should enable staff to act energetically in the best interests of the patients". I have seen more harm done recently through acts of omission-particularly failure to use Section 3 of the Mental Health Act effectively and to prescribe adequate doses of medication-than through acts of commission.

May I, however, through your columns, express my strong reservations regarding the comment that "the provisions of the Code should be attainable within present manpower and financial constraints." It is of course very important that the recommendations of the Code should be realistic. On the other hand it would be a pity if the recommendations were to be too much constrained by fluctuating political and fiscal factors, particularly as there is so much variation throughout the country between regions and even within regions. Surely it would be better to determine an appropriate and feasible standard of care as practised, say, in the best of our centres of excellence and put this forward as an appropriate ideal to be aimed at nationally. The more deprived districts might not at present be able to achieve this ideal. However if this was put forward as a standard of practice to be aimed at the responsibility would then lie clearly with the Health Authorities to provide resources to enable such practices to be carried out in reality. It would of course need to be made clear in the Code of Practice that where standards fall below the recommended ideal due to lack of resources that the responsibility would be with the Health Authority rather than with individual practitioners to rectify the situation.

The Acre \& Homefield

T. PASTOR

Worthing, West Sussex

\section{Consultant staffing figures}

DeAr SIRS

I find the consultant staffing figures quoted in the paper 'The Role, Responsibilities and Work of the Child and Adolescent Psychiatrist' (Bulletin, August 1986, 8, 202-206) surprising. In Norway we are using as a basis for further proposals the staffing levels proposed by the WHO, which are for one team of minimum four members for each 40,000 population. When due allowance is made for the geographical problems in providing the service, the suggestions are that appropriate coverage in Norway will be a minimum of one team for every 30,000 population (that is total population).

The poverty of the British Health Service becomes apparent when the only figures to be mentioned are for irreducible minimums rather than what is required to give an adequate coverage and so some support for those areas which are prepared to challenge the dominance of somatic disciplines in the tight defence required for service development. I am uncertain that the figures quoted would enable a conscientious consultant to fulfil his responsibilities as itemised in the paper.

It is because of the special problems encountered by child psychiatrists in defending budget proposals that the WHO suggestions are so potentially valuable. From outside Britain one sees too many signs of Health Service workers 'giving up'. I hope that these suggestions for the consultant coverage in child psychiatry can be made a touch more enterprising. It is here that the evaluative research of clinical practice suggested in the paper has such an important part to play, along with research into the evaluation of the other consultant responsibilities mentioned.

Per Lasons Vei 17

SIMON WILKINSON

Kolbotn, Norway

\section{Non accidental injury to adults with mental handicap}

Dear Sirs

1. There are clearcut guidelines regarding cases of child abuse and professional staff working with children know how to respond to a situation. In the case of adults with mental handicap (especially moderate to severe) the situation is not so clear. These people, although chronologically adults, mentally remain vulnerable like children.

2. Non accidental injury is defined as a situation where there is definite knowledge or reasonable suspicion that the abuse was, or may be inflicted (or knowingly not prevented) by any person having custody, charge or care of the person. This would include the following categories:-

(a) Physical injury.

(b) Administration of poisonous substances.

(c) Severe or persistent physical neglect.

(d) Medical diagnosis of non-organic failure to thrive. 
(e) Where behavioural and emotional development have been severely neglected.

(f) Sexual abuse.

If non accidental injury occurs in hospital or Local Authority residential accommodation, hospital management or Local Authority can investigate and deal with it, but if the adult with mental handicap lives at home the position is complicated. The law relating to children-the Place of Safety Law-is not applicable to adults even if they are mentally like children. Even the Guardianship Order under the Mental Health Act 1983 cannot be used, as according to the new Definition of Mental Impairment/ Severe Mental Impairment, apart from the arrested or incomplete development of mind, impairment of social and intellectual functioning, there has to be seriously irresponsible and abnormally aggressive conduct by the person concerned. If the parents or carer do not co-operate the only way professionals can respond to the situation is by the Local Authority going to Court to take away the parental rights and assume parental responsibilities. This seems to be a rather drastic step.

I am writing this so that other members who have either dealt with cases of NAI to adults with mental handicap, or have suggestions for dealing with such difficult cases, may like to share their views.

Leavesden Hospital

IQBAL SINGH

Watford, Herts

\section{Psychoanalysis: Science or nonscience DeAr Sirs}

I read with great interest Carola Mathers' article 'Psychoanalysis: Science or Nonscience?' (Bulletin, May 1986, 10, 103-104).

She suggests that if we accept Popper's criterion for the demarcation of the empirical sciences, namely the production and testing of falsifiable theories, then we can exclude psychoanalysis from scientific status 'without further thought'. However, she raises a number of objections to Popper's philosophy of science, which cause her to reject it.

She says that falsifiability is not the same as testability since 'by testing a theory one can prove it to be correct or incorrect'. However, they are the same in the sense in which they are used by Popper: a theory is called falsifiable or testable if it divides the set of all conceivable statements of fact into those with which it is consistent and those which it contradicts or refutes. Perhaps Carola Mathers incorrectly equates falsifiability with falsification (which occurs when the results of a test contradict the predictions of a theory); theories do not have to undergo falsification in order to be considered empirical, but they do have to be falsifiable. Furthermore, it is an essential argument of Popper that by testing a theory one cannot prove it to be correct, since the proof of universal statements by singular statements relies on inductive logic, whose own justification leads either to an infinite regress or the doctrine of apriorism.

Unlike Carola Mathers, I believe the examples she gives concerning the activities of scientists tend to support the idea that the practice of science is described by Popper's philosophy. Scientists do indeed spend much of their time experimentally finding that the results of their tests agree with the predictions of their theories - this is described by Popper as corroboration, and does not amount to proving the hypotheses (since this would require inductive logic). It is only when experimental results are inconsistent with a hypothesis, falsifying it, that a new hypothesis is likely to be formulated. The replacement of Newtonian theory by Einsteinian theory is an excellent example: the general theory of relatively made predictions which differed from classical theory, and in 1919 the total eclipse of the sun allowed measurements of the deflection of light-rays by a mass that corroborated general relativity and seemed to refute (or falsify) classical theory. Thus, classical theory was rejected in favour of general relativity.

The suggestion that scientists unwittingly distort their experiments or observations to generate the results they expect is described by Popper as a 'conventionalist stratagem' to avoid the replacement of old theories by new ones. He cautions: 'it must be left to the investigator. . . to guard constantly against the temptation to employ new conventionalist strategems-a temptation to which psychoanalysis, for example, often succumb'. In this particular case he recommends that the results of inter-subjectively testable experiments are either to be accepted, or rejected in the light or counter-experiments.

In the analytic session, described by Carola Mathers as 'the laboratory of psychoanalysis', a correct interpretation by the analyst may promote a stream of new material from the patient. If an interpretation is derived by the patient, then this might suggest it was incorrect and falsified. However, if a new theory, 'resistance to treatment' is introduced to explain the 'phenomenon of denial' then by this ad hoc hypothesis, psychoanalytic interpretation becomes no longer falsifiable. Popper warns against the introduction of ad hoc hypotheses (another 'conventionalist stratagem') and recommends that auxiliary hypotheses are accepted only if they do not diminish the degree of falsifiability or testability of the system in question. If psychoanalysts have a theory to explain every and any response of their patient, then psychoanalytic theories are no longer falsifiable, and the world in which psychoanalytic theories are true, becomes empirically equivalent to the world in which psychoanalytic theories are false. This is the fate suffered by a discipline when it dispenses with a scientific basis; it raises the question, what use are psychoanalytic theories?

Even if psychoanalysis is considered as nonscientific, then there need not be a polarisation of views between those arguing that 'meaning is more important than scientific status' and those arguing that 'because psychoanalysis is unscientific it is meaningless'. Popper has stated that 'falsifiability is a criterion of demarcation... but not of meaning.... It draws a line inside meaningful language not 